\title{
Assessing the Potential of Participatory Modeling for Decolonial Restoration of an Agro-Pastoral System in Rural Zimbabwe
}

\author{
M.V. EITZEL (D)
}

JON SOLERA

EMMANUEL MHIKE HOVE

K.B. WILSON

ABRAHAM MAWERE NDLOVU

DANIEL NDLOVU

ABRAHAM CHANGARARA

*Author affiliations can be found in the back matter of this article
ALICE NDLOVU

KLEBER NEVES

ADNOMORE CHIRINDIRA

OLUWASOLA OMOJU

AARON C. FISHER

ANDRÉ VESKI

\section{] $\mathrm{u}[$ ubiquity press}

CORRESPONDING AUTHOR:

\section{M.V. Eitzel}

University of California, Santa Cruz, US

mveitzel@ucsc.com

\section{KEYWORDS:}

mixed methods; agentbased model; ecocultural restoration; situational analysis; betweenness centrality; participatory modeling

\section{TO CITE THIS ARTICLE:}

Eitzel, MV, Solera, J, Mhike Hove, E, Wilson, KB, Mawere Ndlovu, A, Ndlovu, D, Changarara, A, Ndlovu, A, Neves, K, Chirindira, A, Omoju, O, Fisher, AC and Veski, A. 2021. Assessing the Potential of Participatory Modeling for Decolonial Restoration of an Agro-Pastoral System in Rural Zimbabwe. Citizen Science: Theory and Practice, 6(1): 2, pp. 1-16. DOI: https://doi.org/10.5334/cstp.339 


\section{INTRODUCTION}

One of the goals of citizen science can be to confront injustice, as in the case of water quality in Flint, Michigan (Gaber 2019). But what do citizen science methods have to offer when injustice involves Indigenous people and colonialism? Colonialism has systematically and intentionally destroyed the lifeways, more-than-human relations, and collective stewardship practices of Indigenous people (Norgaard 2019, Estes 2019). Both the terms "citizen" and "science" are problematic in this context (Eitzel et al. 2017), and projects involving Indigenous groups and allied outsider researchers are more commonly labeled community-based participatory research (Wilson et al. 2018). However, even problematic methods may be successfully repurposed by Indigenous people (Walter and Andersen 2013), so thinking through and testing participatory methods' decolonial potential is therefore relevant. In this study, we engage in a self-reflective process to assess the ability of our participatory modeling to support ecocultural restoration in rural Zimbabwe. To give context for our work, we briefly discuss decolonization, ecocultural restoration, participatory modeling, and the timing of benefits from participatory projects.

Decolonization is often recognized as an ongoing process because colonialism is an ongoing process (contrast with the term post-colonial; Pearce 2019): Colonial harms continue to affect people in many diverse and systematic ways (e.g., mentally and spiritually as well as physically and culturally) (Sium et al. 2012). Decolonization cannot be substituted for any other social justice issue in a metaphorical way: it must address Indigenous people and the realities of continuing suffering and lack of sovereignty over land (Tuck and Wang 2012), or more properly for many groups, country (Pearce 2019). Decolonization can be defined differently in different spaces and contexts (Sium et al. 2012), but most definitions insist that decolonial projects must be led by Indigenous people. In the world of citizen science, this means at least an "integrated" (Chilisa 2017) or "co-created" (Shirk et al. 2012) process, and ideally a community-controlled (Arnstein 1969), "collegial" process (Shirk et al. 2012): Indigenous knowledge-holders must be treated with equal respect to those who have academic degrees (Chilisa 2017). Indigenous people must specify research questions and methodologies, control the products of the research, ensure benefits of projects to their communities, and be able to refuse to participate at any point. Our project, a collaborative process between community members and outsider allies, was explicitly intended to be as community-controlled as possible. In this study, we define decolonization more specifically as advancing Indigenous self-determination in the stewardship of natural resources using culturally appropriate methods, particularly in the process of ecocultural restoration.

Ecocultural or biocultural restoration as a concept originates in response to the broader context of ecological restoration. Ecological restoration seeks to assist an ecosystem in recovering from damage. Examples include repairing eroded landscapes and replanting native vegetation to return the ecosystem to a reference (often pre-colonization) state. However, ecological restoration initiatives have often ignored the role of Indigenous people in dynamically maintaining ecosystems in the targeted pre-colonial state and have reinforced the (nonIndigenous) distinction between human and non-human (Pearce 2019). In response to these theoretical and ethical failures, we use the term "ecocultural restoration," which highlights the importance of restoring culture (e.g., traditions, ceremonies, collective management) as well as ecology, but also emphasizes that these things are not separate (Martinez 1995). "Fixing the world means fixing and restoring the intertwined environmental and social degradation" (Norgaard 2019, quoting Reed) and "restoring processes that enabled a certain cultural engagement with place to continue" (Pearce 2019). Many Indigenous knowledge systems do not divide social from ecological, ethical from practical, knowing from acting, or human from more-than-human (McGregor 2004). Therefore, decolonial ecocultural restoration may also need to rebuild "right relationship" (Kimmerer 2011) with the system as well as function and form that have been disrupted, damaged, and destroyed by colonization and ongoing colonialism (Chilisa 2017). In the Karanga culture of the community we work with in the project described here, the tradition of collective relation and care is Chivanhu, or as it is more widely known from uses in South Africa, "Ubuntu philosophy" (Samkange and Samkange 1980). Decolonial (ecocultural) restoration focuses on situating projects in a sense of place-understanding the local history and current political contexts (Pearce 2019). It also focuses on community capability and decision-making, reinforcing and building Indigenous peoples' resilience, and potentially adapting and using tools and ideas both traditional and contemporary, both colonial and Indigenous (Pearce 2019). In our modeling process, we sought to support ecocultural restoration consistent with Chivanhu, working with the community-based Muonde Trust (a Zimbabwean nongovernmental organization dedicated to supporting Indigenous innovation) in a participatory modeling process. We examined benefits to several ecocultural aspects of the system: individual self-efficacy, development of new landuse policies, and on-the-ground land-use change.

In search of tools to repurpose for decolonial ecocultural restoration, we may find that not all modeling tools are 
equally useful. Some models are better suited to integrate diverse forms of knowledge, are more useful in situations with high uncertainty, and can accommodate participants with different needs and perspectives (Voinov and Gaddis 2017). For example, scenario-oriented modeling can serve well in these kinds of cases (Soleri and Cleveland 2005). Methods like role-playing games and agent-based models (ABMs), in which communities, along with researchers, can simulate different situations, are a large component of participatory modeling frameworks (e.g., companion modelling, Étienne 2014). Participatory process is a crucial element of making beneficial use of models in decolonial restoration. In particular, some Indigenous scholars distinguish between methods and methodologies when assessing the history and potential of a tool to harm their people: Methodology, as conceived by Walter and Anderson (2016), involves first the researchers' standpoint, then the theoretical framing this leads them to choose, and from there, the methods they apply to a question of interest. A method such as a population survey, used by a colonial state to control an Indigenous population, can do (and has done) a great deal of harm. If, however, Indigenous people make use of these methods, raising their own questions and defining their own categories consistent with their own research standpoints, these same methods may be of use. These authors' arguments therefore suggest that how the method is used (and who is driving the process) is just as important or perhaps more important than what method is chosen (Walter and Anderson 2016). In addition, though a tool may (in its form and/or function) tend toward the (colonial) uses for which it was originally built, one way to disassemble that association is to start by changing the methodology: Who is asking the questions and why, and who benefits from the answers? Grounded in these ideas, we further define decolonization in our study as the repurposing of tools of colonial origin for the use of the Indigenous community.

Finally, one important aspect of participatory process is the longevity of benefit. While collaborative modeling approaches often result in immediate benefits in the forms of increased system knowledge and improved decisionmaking processes, the long-term benefits of participatory modeling are not often evaluated (Oteros-Rozas et al. 2015, Falconi and Palmer 2017). Even with the best of intentions, participatory processes of all kinds can become extractive, unintentionally reproducing colonial patterns (Coombes et al. 2014). One way to improve the ability of participatory modeling to contribute to decolonization is therefore to pay attention to short-term, intermediate, and especially long-term benefits (a common framing in program planning and evaluation) (Wholey, Hatry, and Newcomer 2010). Taking a longer-term view of benefits can work toward improving a methodology that intends to repurpose an originally colonial tool (Eitzel et al. 2018). Here, we assess the decolonial ecocultural impacts of our modeling process up to four years after our initial modeling workshops.

\section{METHODS}

This section contains a summary of our community-based process and the mixed-methods approach we used to assess its potential for decolonial ecocultural restoration. For more details, see Supplemental File 1: Appendix A for a thorough (thick) description of our study system and participatory modeling methods, Supplemental File 2: Appendix B for the specific timeline of activities and participants (summarized in Tables 1 and 2), and Supplemental File 3: Appendix C for rich information on our mixed-methods analysis and assessment of the modeling process (including justifications, explanations, and examples).

\section{STUDY SYSTEM: PARTICIPATORY MODELING IN MAZVIHWA COMMUNAL AREA, ZIMBABWE}

In Mazvihwa Communal Area, Zimbabwe, there is an ongoing land management problem that is a product of colonial and post-independence policies: collective management of woodland grazing areas has become uncoordinated, and more and more of these areas are being converted to crop fields. The system is trapped in an unfortunate feedback cycle in which there is detailed knowledge of the problems but little capacity on the part of individuals and even motivated local leaders to collectively improve the situation. The Muonde Trust, a local nongovernmental organization dedicated to supporting Indigenous innovation, wanted to raise awareness of this problem and encourage the community to take action to protect and restore the woodland grazing areas (including sacred forests, or rambotemwa). Muonde has been conducting research on issues of concern to the community in Mazvihwa for the past 35 years, and has often worked with outsider researchers committed to participatory methods. The local research team has members representing Mazvihwa's diversity of clans, villages, genders, education levels, leadership experience, and English language skills, and they have their own organic "free, prior, and informed consent" process of ongoing relationships rather than one-time legal agreements to achieve accountability (Michaels 1993). (Though we do note that formal human subjects approval is also an essential part of collaborative work and should be discussed with communities. We obtained approval through the University of California, Santa Cruz for this study, protocol \#2187.) To address the ongoing concern about 


\begin{tabular}{|c|c|c|}
\hline PROJECT STAGE & OUTSIDER ACTIVITY & COMMUNITY ACTIVITY \\
\hline $\begin{array}{l}\text { Data collection } \\
\text { (1980s-present) }\end{array}$ & $\begin{array}{l}\text { Forming partnerships with community members, } \\
\text { archiving community data }\left(\mathrm{KBW}^{1}\right)\end{array}$ & $\begin{array}{l}\text { Generating initial questions and maintaining research } \\
\text { program over } 35 \text { years (AMN) }\end{array}$ \\
\hline $\begin{array}{l}\text { Preliminary synthesis of data } \\
\text { (2012) }\end{array}$ & $\begin{array}{l}\text { Creating slide presentation on computer to show } \\
\text { accumulated data (KBW) }\end{array}$ & $\begin{array}{l}\text { Working to clean up, correct, and organize data archive } \\
\text { and to co-select topics for data representation (AMN) }\end{array}$ \\
\hline $\begin{array}{l}\text { Determining modeling goals } \\
\text { (2015) }\end{array}$ & $\begin{array}{l}\text { Explaining community research questions to } \\
\text { outsider modelers (KBW) }\end{array}$ & $\begin{array}{l}\text { Sharing research questions of importance to Muonde } \\
\text { and the community in Mazvihwa (AMN) }\end{array}$ \\
\hline $\begin{array}{l}\text { Conceptual model design } \\
\text { (2015) }\end{array}$ & $\begin{array}{l}\text { Choice of model type (MVE, KBW), initial design of } \\
\text { agent-based model (MVE, KN, OO, AV, KBW, JS) }\end{array}$ & $\begin{array}{l}\text { Feedback on elements that needed to be included in } \\
\text { the model (AMN) }\end{array}$ \\
\hline Model implementation (2015) & Coding in Netlogo (MVE, KN, JS) & \\
\hline Model calibration (2015-2017) & $\begin{array}{l}\text { Adding model behaviors, refining parameters } \\
\text { (MVE, KBW, JS) }\end{array}$ & Feedback on accuracy of coarse model behavior (AMN) \\
\hline $\begin{array}{l}\text { Verification, simulation, and } \\
\text { validation (2016-2017) }\end{array}$ & $\begin{array}{l}\text { High-performance computing (HPC) test of many } \\
\text { parameter combinations (MVE, JS, ACF) }\end{array}$ & $\begin{array}{l}\text { Testing scenarios in workshops, commenting on model } \\
\text { behaviors, suggesting additional features (AMN, AN, } \\
\mathrm{AbC}^{2} \text {, AdC, DN, EMH, and Muonde team) }\end{array}$ \\
\hline $\begin{array}{l}\text { Discussion of results and } \\
\text { dissemination of conclusions } \\
\text { (2017-2020) }\end{array}$ & $\begin{array}{l}\text { Initial community workshops, academic papers } \\
\text { (MVE, KBW, JS) }\end{array}$ & $\begin{array}{l}\text { Initial and later community workshops showing model } \\
\text { to leaders and young farmers (EMH, AN, DN, AbC, AdC, } \\
\text { AMN and Muonde team) }\end{array}$ \\
\hline $\begin{array}{l}\text { Translation of results into } \\
\text { action }(2017-2020)\end{array}$ & & $\begin{array}{l}\text { Advocating for policy change and piloting households } \\
\text { in fallow fields (Muonde team) }\end{array}$ \\
\hline
\end{tabular}

Table 1 Participatory modeling processes; authors' involvement is indicated by their initials (see Supplemental File 1: Appendix A and Supplemental File 2: Appendix B for a detailed accounting of activities and participants in each activity).

${ }^{1} \mathrm{KBW}$ is an unusually embedded outsider who has engaged deeply with Muonde's research processes for 35 years.

${ }^{2} \mathrm{AdC}=$ Adnomore Chirindira; $\mathrm{AbC}=$ Abraham Changarara.

\begin{tabular}{|c|c|c|}
\hline PROJECT STAGE & OUTSIDER ACTIVITY & COMMUNITY ACTIVITY \\
\hline $\begin{array}{l}\text { Workshops } \\
\text { (2016-2017) }\end{array}$ & Taking notes on original workshops (MVE) & $\begin{array}{l}\text { Organizing initial workshops (AN, AMN, AdC2); } \\
\text { taking notes in initial workshops (EMH, DN); } \\
\text { explaining model to team in initial workshops (AbC); } \\
\text { running later workshops with local leaders (EMH, AN, } \\
\text { AMN, others on Muonde team) }\end{array}$ \\
\hline $\begin{array}{l}\text { Qualitative } \\
\text { assessment } \\
\text { (2016-2020) }\end{array}$ & $\begin{array}{l}\text { Interviewing collaborators via email and text message about } \\
\text { the modeling process, coding notes for time chart, mining for } \\
\text { representative quotes, creating social worlds map (MVE); } \\
\text { situational analysis of elements in modeling process and their } \\
\text { connections (MVE, JS, KBW'1). }\end{array}$ & $\begin{array}{l}\text { Conducting group interviews of Muonde team about } \\
\text { modeling process, reporting on community reactions } \\
\text { and use of model after initial workshops (EMH, AN, } \\
\text { Muonde team) }\end{array}$ \\
\hline $\begin{array}{l}\text { Quantitative } \\
\text { assessment (2020) }\end{array}$ & Statistical analysis of trends in new households (MVE) & $\begin{array}{l}\text { Measurement of new households in fallow land } \\
(\mathrm{EMH}, \mathrm{DN})\end{array}$ \\
\hline $\begin{array}{l}\text { Creating this paper } \\
(2018-2020)\end{array}$ & $\begin{array}{l}\text { Drafting initial versions, polishing final versions for } \\
\text { publication (MVE); } \\
\text { editing and giving feedback on drafts (JS, KBW, KN, OO, AV, ACF) }\end{array}$ & $\begin{array}{l}\text { Detailed feedback especially on Introduction, Results, } \\
\text { and Discussion (EMH); } \\
\text { higher-level feedback (AMN, AdC, AbC, DN, AN, } \\
\text { facilitated by EMH) }\end{array}$ \\
\hline
\end{tabular}

Table 2 Modeling assessment processes; authors' involvement is indicated by their initials (see Supplemental File 1: Appendix A and Supplemental File 2: Appendix B for a detailed accounting of activities and participants in each activity).

${ }^{1} \mathrm{KBW}$ is an unusually embedded outsider who has engaged deeply with Muonde's research processes for 35 years.

${ }^{2} \mathrm{AdC}=$ Adnomore Chirindira; $\mathrm{AbC}=$ Abraham Changarara.

land use, outsiders collaborated with Muonde's leadership and research team to construct an $A B M$ representing the crops, woodland, and livestock in Mazvihwa (Table 1 and Figure 1 below; see also Eitzel et al. 2020a, b). The Muonde team then used the model as a discussion tool to encourage local leaders to make policy changes that allowed the reuse of fallow fields, and inspired young farmers to seek homesteads there. 

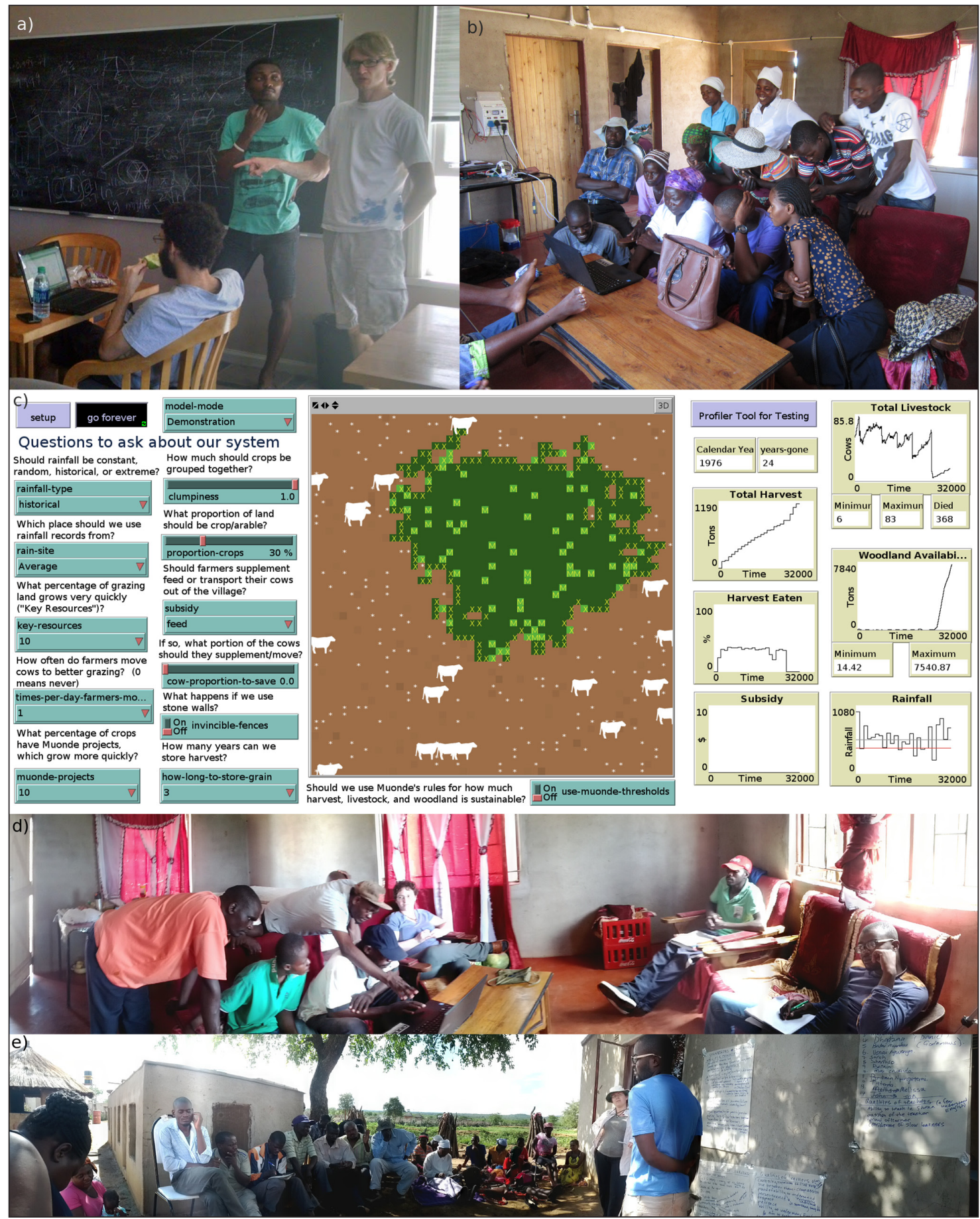

Figure 1 The modeling process. (a) Initial model development at Santa Fe Institute Complex Systems Summer School, showing coauthors with quantitative modeling skills discussing an early stage of the model; these coauthors were also learning to program in NetLogo and corresponding with Muonde Trust researchers via videoconference (Skype). (b) Small-group workshop with Muonde Trust coauthors demonstrating and explaining the model to the other members of the community-based research team. (c) Computer screen capture of the final version of the model while it is running, at left showing the choices made by the user, in the middle displaying the visualization of the model's current state (showing cows' position, the spatial configuration of the crops and woodland, and how much biomass is on each patch-brighter colors have more biomass), and on the right tracing the behavior of key variables over the course of the simulation (for example, rainfall, numbers of cows, and accumulated total harvest). This is the interface developed by the Santa Fe Institute summer school participants in (a), and it is the interface the Muonde Trust researchers are interacting with in (b) and (d) (and later showed to local leaders). (d) Small-group workshop showing note taking by observers (also Muonde Trust researchers). (e) Wholegroup workshop to discuss the real system and how the model generates new thoughts on its management (facilitated by outsider researcher, with assistance and translation from Muonde Trust researchers). Photo credits: M.V. Eitzel, J. Solera; used with permission of all those pictured. 


\section{MIXED-METHODS ASSESSMENT OF PARTICIPATORY MODELING PROCESS}

To assess the potential of our process to enable decolonial restoration, we used a variety of quantitative and qualitative methods (Table 2). During the process of creating, evaluating, and applying the model, we kept notes on community and researcher reactions, and we interviewed participants via emails, text messages, and in-person focus groups. We then created a timeline of our modeling process to track when the community was involved and how, and developed short-, medium-, and longterm assessments of benefit. In the short term, we used observations of community members during workshops and quotes from focus groups that followed to assess increases in confidence and self-efficacy about the model. In the medium term, we used quotes from later focus groups to assess how leaders' and community members' thinking changed about the land-use problem, including changes in local policies around re-cultivating fallow fields. And in the long term, we recorded on-the-ground changes in land use, counting how many new households were established in fallow fields rather than in the woodland area, and tested the trend statistically (see Supplemental File 3: Appendix C and Supplemental File 4: Appendix D).
Finally, to understand how this process worked, we made a network diagram of all the elements in the system (people, concepts, technologies, organizations, and on-the-ground aspects of the farming) and whether they connected to each other (see Supplemental File 5: Appendix E and Supplemental File 6: Appendix F for lists of elements and their relationships), and investigated which of these elements was most important in facilitating connections with other elements ("betweenness centrality," Prell 2012).

\section{RESULTS \\ SHORT-TERM CHANGES: PERSONAL EFFICACY AND LEARNING}

We noted that many participants learned something about one or more of the three contexts of our model development process: computing (including HPC and software development), complex systems (associated with the Santa Fe Institute summer school), and communitybased research (including the historical and political context of Mazvihwa Communal Area). Their changes in understanding of different contexts are diagrammed in Figure 2, with key quotes and observations supporting these moves given in Supplemental File 3: Appendix C.

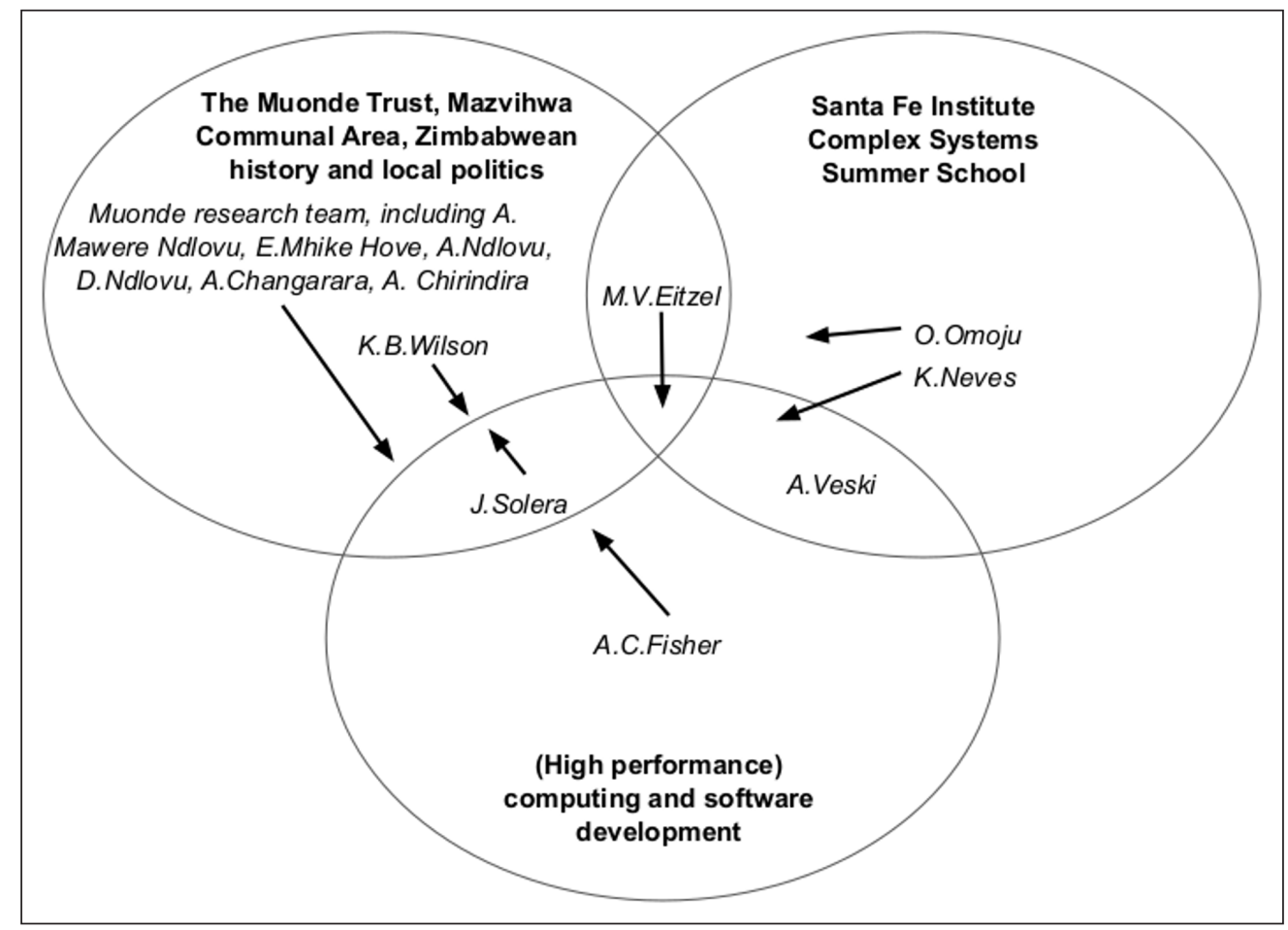

Figure 2 The movement through different contexts of participants in the modeling process. In bold text are the three primary contexts of our process (computing, complex systems, and the study system/community-based research; represented by the three circles), and in italic text are the authors and participants. Many participants began with a focus in one of these contexts and then shifted toward one or more of the other contexts during the process (diagrammed using arrows from starting location to ending location); in particular, the first author ultimately sat at the intersection of the modeling, agro-ecosystem, and complex systems science context, as Étienne et al. indicate is necessary for a participatory modeling facilitator (2014). 
Community members learned about computers and how the model worked, while outsider researchers learned both new computing techniques as well as how the model could be used by the community. Both quotes and behaviors indicated increased self-efficacy for participants in novel areas, especially the community participants, who reflected: "We thought it's a complicated scientific thing but now we see it's simple and very useful," and that the model could "Help us differentiate our dreams and reality." Community members also demonstrated confidence in using the model, developing and comparing different scenarios, speculating on mechanisms behind model behaviors, and generating ideas for other issues for which they could use a model like this (e.g., the problem of baboons eating crops).

\section{MEDIUM-TERM CHANGES: INCREASED COLLECTIVE ACTION}

In initial workshops, the community discussed a variety of challenges associated with managing their agro-pastoral system. A year later, the community reflected that "We used to think what we have was the natural state of things (taiti zvinozviita zvega) but after seeing this model we realize that our basic things in life interact and complement each other and we human beings are the system drivers." Muonde and other community members have put this idea into action, including discussing fencing the remaining rambotemwa (sacred forests), doing significant work on a biocultural protocol for the whole area designed to protect collective resources and to keep the community involved in decision-making, and establishing a rambotemwa protection committee. (Note that this occurs in the context of a multinational diamond mining corporation prospecting into the heart of Mazvihwa.) In addition, in a fully ecocultural practice of restoration, cultural ceremonies (bira), including revitalized traditional songs and dances, have accompanied replanting of native trees to restore the rambotemwa.

Regarding the community's collective view of who in the community is responsible for determining and enforcing land-use decisions, some initially blamed the chiefs for not stopping people from cutting woodland and degrading the ecosystem in various ways; to which the chiefs who were present in the workshop responded that it is difficult to control people, and especially those in the newly resettled areas. However, by the final workshops, the group agreed that it was time to "stop blaming the local authorities for everything, it's our collective responsibility."

Finally, the chiefs and local leaders in Mhototi Ward (one of four Wards in Mazvihwa) demonstrated in their workshops their shifting understanding of the larger landuse problem: One leader said, "I quickly thought of this situation where our agro-pastoral life will no longer be sustainable," while another remarked, "[the model] gives you what you want, if you want the system to be corrupt it gives you corrupt but if you want to be frank it gives you what you deserve. You have to be bold to face the reality. The only difference is that it is a machine and makes us God for few minutes deciding what, when, how much..." Based on this change in understanding, the chiefs have given their blessing to re-cultivate the fallow fields of absentee owners: After seeing the model, one chief (headman) said they would identify idle fields and give people those areas, and if the owner returned, "he will be given his/her land or given [land] somewhere else." This strategy was not possible before because customary law prevented the repurposing of people's fields just because they were fallow, but with the chiefs' blessing and widespread recognition of new circumstances this policy can allow new homesteads to be established in fallow fields rather than converting remaining woodland grazing area.

\section{LONG-TERM CHANGES: SHIFTS IN LAND USE}

The first household established in the fallow fields was in 2015 in Mudhomori Village. Following the new community policy emerging from the workshops in 2017, new households were established in fallow fields in multiple villages throughout Mhototi Ward in Mazvihwa (Table 3). The numbers increased each year, for a total of 41 new households by the end of 2019, and even accounting for differences due to individual villages and the timing of the policy development, the increasing trend is statistically significant ( $p=0.045$ ). The spread of the new practice does not appear to be simply diffusing away from Mudhomori, but rather appears in more distant villages because the information travels in leaps (for example, through the visits of key Muonde members to particular villages).

\section{BRIDGING ELEMENTS IN OUR MODELING PROCESS}

The elements of the system that were most important in bridging between other elements (Table 4) included some we predicted (the model itself, the Muonde Trust, the leadership of Muonde, and the lead researcher involved in creating the model), and some we had not (the data archive collected by the Muonde research team upon which the model is based, the concepts of ecology and climate change, and Mazvihwa farmers in general).

These facilitators are shown in Figure $3 a$, which displays a network showing all the elements in the system and whether they interact with each other. We highlight the system elements with the top 10 highest betweenness by making them larger than the others (see Supplemental File 7: Appendix $\mathrm{G}$ for a version with the elements labeled). In Figure $3 b$, we show on-the-ground system elements larger than other nodes, allowing us to see that the model 


\begin{tabular}{|c|c|c|c|c|c|c|}
\hline YEAR & 2015 & 2016 & 2017 & 2018 & 2019 & VILLAGE TOTALS \\
\hline $\begin{array}{l}\text { MODELING } \\
\text { EVENTS }\end{array}$ & $\begin{array}{l}\text { Demonstration } \\
\text { homestead } \\
\text { established }\end{array}$ & $\begin{array}{l}\text { Model } \\
\text { initially } \\
\text { presented }\end{array}$ & $\begin{array}{l}\text { Workshop } \\
\text { with local } \\
\text { leaders }\end{array}$ & $\begin{array}{l}\text { Showing model } \\
\text { to young farmers }\end{array}$ & $\begin{array}{l}\text { Showing model } \\
\text { to young farmers }\end{array}$ & \\
\hline \multicolumn{7}{|c|}{ NUMBER OF NEW HOMESTEADS IN THE FALLOW FIELDS, FOR EACH VILLAGE IN EACH YEAR } \\
\hline Mudhomori & 1 & & 2 & 2 & 7 & 12 \\
\hline Magwidi/Muguti & & & & & 3 & 3 \\
\hline Gozho & & & & 5 & & 5 \\
\hline Magetsi & & & & & 2 & 2 \\
\hline Manhivi & & & 1 & 2 & & 3 \\
\hline Jimu & & & & & 3 & 3 \\
\hline Chinguo & & & & 2 & 1 & 3 \\
\hline Mhike & & & 2 & 3 & 2 & 7 \\
\hline Chikwati & & & & & 3 & 3 \\
\hline YEAR TOTALS & 1 & & 5 & 14 & 21 & 41 \\
\hline
\end{tabular}

Table 3 Spread of land-use policy innovation in Mazvihwa Communal Area (villages are listed in order of roughly increasing distance from Mudhomori).

\begin{tabular}{ll}
\hline NAME & $\begin{array}{l}\text { BETWEENNESS } \\
\text { CENTRALITY }\end{array}$ \\
\hline Model & 163 \\
\hline Muonde data archive & 139 \\
\hline K.B. Wilson (Muonde co-founder) & 92 \\
\hline $\begin{array}{l}\text { A. Mawere Ndlovu (Muonde Executive } \\
\text { Director and co-founder) }\end{array}$ & 83 \\
\hline A. Ndlovu (Muonde Operations Director) & 74 \\
\hline Climate change (as a concept) & 65 \\
\hline Muonde Trust & 61 \\
\hline M.V. Eitzel (lead outsider researcher) & 60 \\
\hline Ecology (as a concept) & 58 \\
\hline Mazvihwa farmers & 51 \\
\hline
\end{tabular}

Table 4 Network centrality measures for bridging elements that facilitated the most connections with other elements (specifically, those with the 10 highest betweenness centrality scores) in the modeling process.

connects to some but not all of them. In addition, we note that the lower-right side of the network is largely Zimbabwean/community-oriented elements, while the upper-left side of the network is associated more with the outsider collaborators and technical/modeling elements (elements involved in both contexts lie in the middle). In Figure 3c, we show that the Muonde Trust is highly connected to on-the-ground practice-oriented elements but also to modeling- and policy-oriented elements. In general, the Zimbabwean part of the network is more densely connected, as is appropriate for the communityand place-based nature of the work.

\section{DISCUSSION}

Through our assessment of our participatory modeling process, we identified several key features that underlie our success in doing community-controlled work, making on-the-ground change, and seeing benefit on multiple timescales. First, community involvement in key stages of the process is important in ensuring benefit. Owing to this sustained community engagement, the model was understandable to many different audiences. This made it a useful object the community and local leaders could gather around to discuss the real system, and in that way to restore collective management and enable decolonial restoration of social and ecological aspects of the system. Finally, Muonde's relationships with local leaders and reputation for powerful Indigenous-based research and innovation meant that the model could be employed in this way.

\section{COMMUNITY LEADERSHIP IS ESPECIALLY IMPORTANT IN PARTICULAR STAGES OF MODELING}

The Muonde team reflects that the model was successful because it came at a critical time when people (ordinary Mazvihwa residents) had concerns with the pace that 


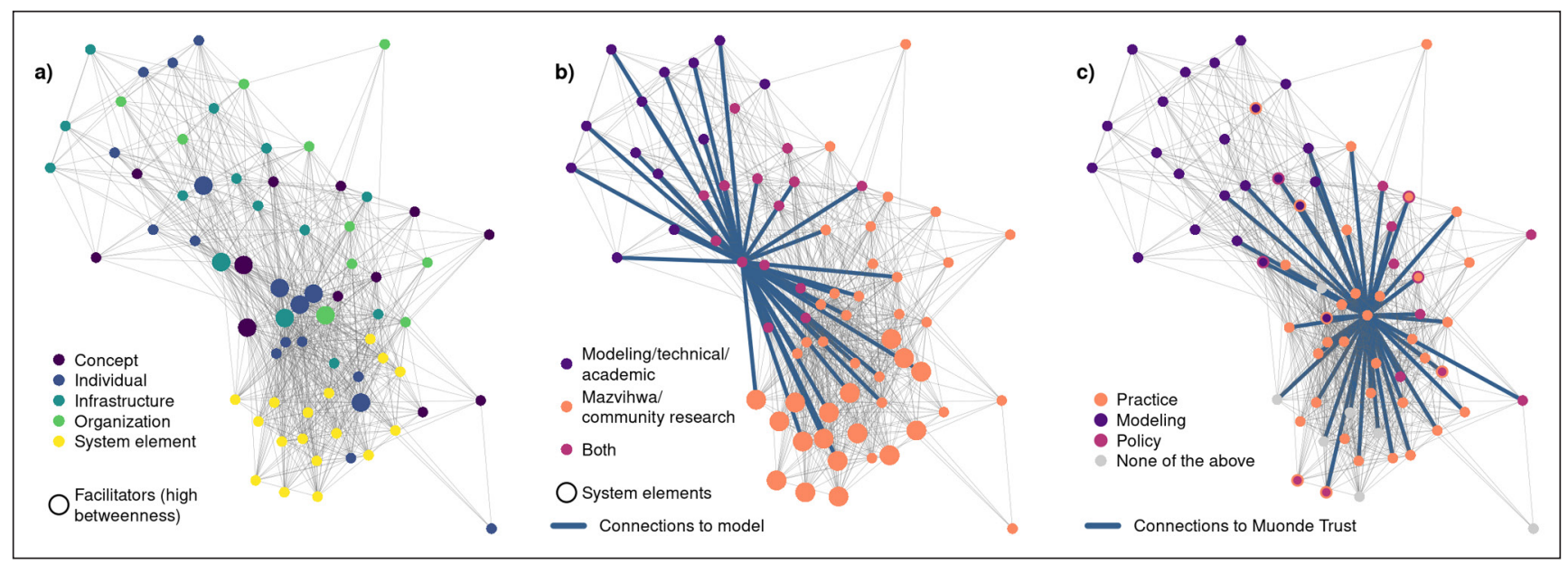

Figure 3 Network diagram showing the connections between different elements of the situation. (a) Element types and key bridging facilitators: Elements are colored by their category; those with the top 10 betweenness scores are larger. (b) Model as boundary object: Elements are colored based on their predominant research context-Mazvihwa Communal Area/community-based (orange), academic/modeling/technical (purple), or some combination of both (magenta). Within that, the on-the-ground study system elements are larger, and the model's connections to other elements are shown in thicker lines. (c) Muonde as innovation facilitator: Elements are colored by their community context - modeling (purple), policy (magenta), on-the-ground practice (orange), or none of the above (gray). Elements with multiple contexts appear with their dominant context color in the center and a border color that corresponds with their secondary context. Connections to the Muonde Trust are shown in thicker lines.

grazing land was being turned into new homesteads and fields. This timing is no accident, because Muonde's co-founders sought out the model precisely to address this question of current concern to the community. In addition, the data we used were familiar to the community researchers who had gathered it over the previous three and a half decades. Therefore, the model's building blocks (questions and data) both came directly from the community. The ability to focus these steps of model development on community needs was made possible via pre-existing long-term relationships and community-driven approaches to working with outsiders (see Supplemental File 1: Appendix A for more detail on Muonde's history).

In addition, though much of the technical implementation was done by outsider modelers, Muonde members were involved in the design, calibration, and validation of the model (Eitzel et al. 2020a). This meant that they were involved in the simplification of the system as it was represented in the model, ensuring that enough complexity was still retained to make the model useful and recognizable to the community. One of Muonde's founders commented that "[For] each dimension [of the model], they were like 'yes if we build stone walls, will our mombes [cows] die?' Enough [realistic] dimensions helps them think about it." Also important was creating an accessible user interface-for example, framing model input choices as simple questions in English that could be easily translated into Shona (the language spoken in Mazvihwa). These aspects also contributed to the community members' improved sense of self-efficacy in regard to the model and computers in general.
Finally, it was particularly important for the community to lead the communication of results and the application of the model. Because the Muonde team had the hardware (computer), software (model), and skills to run them (partly because of their many years of research experience, and partly because young people were involved who had already had experience using computers), the communitybased organization was able to decide who saw the model. Muonde's team suggests that the model was successful in making change because it was presented to the right people first, namely the local traditional authorities-the Chief, the ward head (machinda), and the individual village heads (sabhuku) — who make decisions about where to stay, farm, and graze. This process reminded people, especially Chiefs and village heads, about past droughts and the need to rethink and reorganize agro-pastoral management.

\section{THE MODEL AS A BOUNDARY OBJECT IS UNDERSTANDABLE TO DIFFERENT AUDIENCES}

The model had links spanning the community-based and technical aspects of the modeling process (as represented in the situational map, (Figure 3b). It therefore acted as a boundary object (Star and Griesemer 1989) - an entity that can travel between contexts, speak to different audiences, and yet retain its identity as a single object. In many collaborative projects, models serve as boundary objects to reveal common ground as well as differences (Kalafatis et al. 2018) or to facilitate dialogue between different stakeholders (Yung et al. 2019). Muonde's research team suggests that the model was convincing because it reflected the realities 
in Mazvihwa and was therefore familiar to the community and to local leaders (the boundary object's connections to the community-based aspects of the situation).

The model's function as a boundary object connecting with technical aspects of the situation also served the need for publication and sharing of the model with audiences outside Mazvihwa. Publication can advance communitybased research by giving credit to the work of interdisciplinary, community-oriented, academic scholars and by raising the awareness among scientific and modeling audiences of community-based research. In addition, the improvements made to the model in the process of making it legible to academic audiences also enhanced its functionality for Muonde: A more reliable, faster-running model was easier to use in workshops as well as for calibrating and validating the model quantitatively and qualitatively (Eitzel et al. 2020a), and it made the model more recognizable to the community. That said, the time spent on more precise calibration and validation processes was not necessary for community use (However, it was necessary for publication: Peer reviewers of papers presenting the model asked for justifications the model's parameters and structures). So some-but not allof this technical validation directly benefited the community.

\section{THE COMMUNITY COULD GATHER AROUND THE MODEL TO THINK COLLECTIVELY ABOUT RESOURCE MANAGEMENT}

Muonde was able to use the model as a catalyst for leaders and community members to see the whole agro-pastoral system and its challenges, partly because the model represented Muonde's accumulated research-based and experience-based knowledge in a way that had its own authority. Muonde had piloted the redevelopment of fallow fields before the model, and concerns about conversion of woodland were prevalent in Mazvihwa. However, local leaders made changes to land-use policy only after attending Muonde's workshops and seeing how the model demonstrated that continuing to increase agricultural land will eventually lead to the loss of other benefits. The leaders receive payment for new homesteads established in the woodland grazing area, but do not receive compensation for redevelopment of fallow lands. Therefore, the model was needed to work against the incentives in a system rendered dysfunctional that led chiefs to continue to fragment the grazing area. Since the modeling workshops, one chief has said "We were all dead denying new technological ways, not knowing they can tell us where we are coming from and where we are heading. With this thing now we can sustainably organise and protect two sources of wealth in a rural community, Land and Livestock."

The model's technical nature could make it seem either more authoritative or more suspect: Muonde's team comments that the model had some authority because it was presented on a computer, though people in rural areas (especially older community members) can often be suspicious of technical tools. However, community members' experience with cellphones helped people to see the value of technology, even when it originates from former colonizers. Because a few young people in Mazvihwa use computers for games and movies, the elders saw the value of computers when the model arrived. Because the model had the authority of a technical object, but also was built from Muonde's data and answered their questions, it became a way for the community to gather together to address a problem. When everyone can follow new rules together, they are more likely to be willing to make choices out of more than just self-interest (Ostrom et al. 1999). Thus, co-designing the model explicitly as a discussion or learning tool facilitated cooperation among local stakeholders (Le Page and Perrotton 2017).

Muonde's approach, both with the model and in general, has been to consistently involve local leaders and respect their authority, while demonstrating that innovations and solutions can come from everyone. Together, Muonde and the model help chiefs to resist incentive structures that result in collective harm to the social-ecological system, and as the chiefs are seen to care for the system and the community, faith in traditional authority is also reinforced. This is much improved from the situation in early workshops where the community blamed the chiefs for not controlling deforestation, and the chiefs complained that no one obeys them. In this sense, the modeling process helped to restore important parts of chivanhu through improved collective self-determination and also through reinforcement of valued elements of traditional authority. The traditional leaders in Mhototi Ward will be able to communicate the necessity and benefits of their new land-use policies to other traditional leaders in their monthly and quarterly meetings, so there is potential for the practice to spread by word of mouth from both farmers and local authorities. This parallel process means that in the future there could be both individuals wanting to apply the new rules and also authorities willing to allow it. In fact, Muonde researchers also observed households in fallow fields outside Mhototi Ward, so the word is spreading beyond our initial group in unknown ways.

\section{MUONDE'S ROLE AS A COMMUNITY-BASED ORGANIZATION FACILITATES THE SPREAD OF INFORMATION}

Not all community-based organizations are as well connected as Muonde is, and this connectedness was a key factor in our success in moving the agro-pastoral system toward decolonial restoration. In addition to their heavy emphasis on innovating and sharing sustainability practices 
within the community (of which they are themselves members), Muonde has also cultivated good relationships with local leaders (both traditional chiefs and elected officials), giving them the potential to influence policy as well as practice. Interventions that involve key stakeholders and understand their constraints and conditions can facilitate lasting benefits (D'Aquino and Papazian 2014). And because Muonde also has an established process for working with outsiders who can teach useful skills, they are able to engage in making a model that they can use to influence both policy and practice. They are therefore positioned to move between all three parts of this process (modeling, policy, and practice), and their pre-existing social networks and processes (Eitzel et al. 2016) were absolutely essential in seeing on-the-ground benefit from our modeling process. And indeed, linking with well-connected and well-grounded local community organizations is a key recommendation for participatory modeling methods (Étienne 2014).

Social networks analysis has long identified the importance of both network structure and the centrality of individual entities in spreading innovations (Valente 2006). Muonde is just such a trusted information source to the people of Mazvihwa. Because Muonde's team is itself diverse, including both men and women, young people and elders, members of traditional ruling clans as well as other clans, and people from villages across Mazvihwa, training that reaches the team already reaches a diverse group that is positioned to share new ideas with people in their villages, clans, and other social groups. Community members remarked at one of Muonde's modeling workshops: "Let us conduct more workshops of this caliber. How can we make sure each and every community member [gets] to see and be involved in this?" This sentiment is typical of Muonde's way of working: They have a long history of using research as a process of self-actualization, helping people in their community feel that they can determine what questions are most important to investigate, and can then answer these questions themselves. This follows a research strategy grounded in Ubuntu (chivanhu) ethics to promote "socially relevant research by the people, with the people to address their needs" (Chilisa 2017). This is a large part of how our modeling process improved self-efficacy around the model and computers. Muonde is also creative in working with the assets they have: When resources for large workshops became scarce, the team continued to show the model to small groups of farmers, demonstrating the importance of establishing their new homesteads in fallow fields rather than deforesting the woodland grazing area. This strategy was effective: Young farmers are advocating for the new practice by asking for further workshops for other community members and leaders.

\section{LIMITATIONS AND OPPORTUNITIES FOR GROWTH}

Ideally technical skills will continue to spread such that in the future communities can choose which type of model they use, and even better, do the programming themselves (the implementation stage). In this first-generation effort in Mazvihwa, the outsider modelers on our collaborative team specifically chose an interactive modeling tool that could encourage playful engagement rather than dictating answers. In fact, NetLogo, the programming language used to create the model, was originally intended for teaching modeling (Wilensky and Stroup 1999). The use of ABMs as discussion tools is in line with similar projects done elsewhere in Zimbabwe (Lynam 2003, Perrotton et al. 2017), and ABMs are a common choice for communitybased modeling (Étienne 2014). That said, we envision a future in which the Muonde research team could use a model of their choosing and write the code themselves, or find other tools to achieve their purposes. However, in the current situation, our team followed the idea of Indigenous peoples embracing the re-purposing of a mainstream tool for their own ends (Walter and Andersen 2013). Therefore, it was critically important for outsiders to open possibilities for increased Indigenous leadership at every stage in the modeling. More generally, if the use of an interactive tool like an ABM is not feasible, then outsiders must ensure that questions and data are aligned with community priorities and experience, and that results are provided in a way that can be used by the community.

There can be both overlap and disagreement between scientific and Indigenous theory (Soleri and Cleveland 2005, Hartman et al. 2016), and ideally a modeling process should involve some evaluation of different bodies of theory about the system of interest, as well as careful investigation of when traditional and outsider theories seem most useful in understanding the system. This should be done delicately, however, to avoid reinforcing colonial patterns of engaging Indigenous ways of knowing primarily by "validating" them with Western knowledge. Our modeling process did not explicitly consider the community's Indigenous theories about the functioning of their agroecosystem. This was because the core landscape ecology ideas used in this model-how livestock, agriculture, and woodland interact-already showed high congruence with Indigenous ideas, and both sets of theories are at odds with the kinds of technocratic agricultural knowledge that dominated colonial and post-independence modernization interventions (Mukamuri, 1995; Wilson, 1989, 1990, 1995). However, certain theoretical constructs in the model (for example, conservation of energy and biomass) have no obvious analogue in Indigenous theory (though they are not in contradiction to the community's expectations). 
Other more practical limitations in our process included the lack of ongoing resources available to teach these skills in the long term or to develop the model further. And though Muonde had the computer and the model, outsiders were physically present only for short periods, and much of their assistance was virtual, via text message. Eventually, problems occurred with the technology that could not be handled from a distance, which necessitated a different way of sharing the model in future presentations and limited further model development. These problems are typical of the systemic issues of grant-based research institutions and projects, and though we worked to make the project as participatory and open-ended as possible, limitations multiplied when funding ended. Institutional changes might make it more possible for longer-term funding for this kind of work, and better internet and electrical infrastructure in Mazvihwa would improve their ability to run the model for longer and to get technical support from outsider collaborators. We also caution that our process relied on key individuals, including several specific Muonde research team members and the first author; if these individuals are not able to continue working together, either due to lack of funding or for other reasons, the model may not generate additional benefits. Generally speaking, projects that benefit from longer-term relationship-building processes may result in better results on the ground.

\section{CONCLUSIONS}

Our modeling approach was successful on several timescales and from several different angles: increased selfefficacy and learning, improved collective action, and onthe-ground land-use change. Our modeling process in no way takes credit for the improved governance in Mazvihwa around land-use. Muonde's system knowledge, network, and process are largely responsible for this success, as are the decisions of individual farmers, the willingness of the chiefs and other local leaders to consider new policies, and the desire of residents of Mazvihwa to rebuild collective governance traditions. However, the model provided a critical tool for the Muonde Trust to advocate with local leaders and community members, and the tool could function in this way because it had been developed with and for the community (Chilisa 2017). The solutions applied by the community to address their land-use concerns were wholly their own, and in fact were not even represented in our model (settlement in and recultivating fallow fields)so the model did not dictate the community's actions; in all these senses, we have made movement toward decolonial ecocultural restoration. In the future, perhaps outsiders will not be necessary to facilitate communitybased modeling, but for the present, at least in our case, outsiders and community members had complementary skills and knowledge (Fortmann 2009). Our work is part of a recent surge in participatory modeling (Voinov et al. 2016), which shows that many modelers are seeking to engage in projects that will actually benefit decision-makers and local stakeholders. And the modelers in our process did show increased understanding of community contexts through their direct experience in this project, demonstrating the benefits of practical community-based training for modeler-allies. We focused in this paper on transformation and benefit for the community, but future work should investigate how outsider partners and their future work are changed by participating in collaborative processes.

Our critical evaluation of our own process corresponds to Chilisa's "third-space" approach that goes beyond simply integrating outsiders with Indigenous knowledge holders (Chilisa 2017). We found that our methods of analysis ultimately allowed us to understand and share more about how our modeling process generated benefit. Muonde researchers believe that the model will continue to be useful because it is fundamentally theirs, stating collectively that "this model is forever community owned. The good thing is it was designed by the community people for the community with appropriate outside technical aid." We are pleased with the achievements of this project, and we hope there will be ways to continue this positive momentum and spread it to other communities. We also hope that citizen science practitioners and outsider modelers can learn from our experiences, enabling them to do more effective and supportive participatory work. Future work should also examine how long-term processes of collaboration can be supported institutionally, improving chances of long-term benefit for communities.

\section{DATA ACCESSIBILITY STATEMENT}

The data underlying the results in this paper are available in the Supplemental Files.

\section{SUPPLEMENTARY FILES}

The Supplementary Files for this article can be found as follows:

- Supplemental File 1. Appendix A: Thick description of study system and modeling process. DOI: https://doi. org/10.5334/cstp.339.s1 
- Supplemental File 2. Appendix B: Time chart indicating when modeling activities occurred. DOI: https://doi. org/10.5334/cstp.339.s2

- Supplemental File 3. Appendix C: Mixed methods modeling process assessment details, and data behind Figures 2 and 3. DOI: https://doi.org/10.5334/cstp.339.s3

- Supplemental File 4. Appendix D: R code to make Figure 3, Appendix $\mathrm{H}$, and also to do the test of the time trend in number of households. DOI: https://doi. org/10.5334/cstp.339.s4

- Supplemental File 5. Appendix E: Table of element information underlying Figure 3. DOI: https://doi.org/10.5334/ cstp.339.s5

- Supplemental File 6. Appendix F: Table of link information underlying Figure 3. DOI: https://doi.org/10.5334/cstp.339.s6

- Supplemental File 7. Appendix G: Larger version of Figure 3a with labels. DOI: https://doi.org/10.5334/cstp.339.s7

\section{ETHICS AND CONSENT}

The University of California, Santa Cruz Institutional Review Board, Office of Research Compliance Administration, has reviewed the use of human subjects in this project and has determined that the project is exempt from further IRB review (UCSC IRB Protocol \# 2187) under category 2: Community responses quoted or referred to in the paper and appendices are anonymized, and the responses to our questions would not reasonably place subjects at risk of physical, economic, or social harm even if accidentally disclosed outside of the research. In addition, the project engaged with the community through their own preferred collaboration protocols, described in the main text and appendices.

\section{ACKNOWLEDGEMENTS}

We acknowledge all the members of the Muonde Trust who have worked on the research over the years, and especially the participants in our modeling workshops: Handsome Madyakuseni, Austen Mugiya, Tatenda Simbini Moyo, Britain Hove, Nehemiah Hove, Khaniziwe Chakavanda, Simon Ndhlovu, Sikhangezile Madzore, Innocent Ndlovu, Blessed Chikunya, Maria Fundu, Lucia Dube, Guilter Shumba, Ndakaziva Hove, Sarah Tobaiwa, Moses Ndhlovu, Adnomore Chirindira, Oliver Chikamba, Cephas Ndhlovu, Esther Banda, Egness Masocha, Abraham Ndhlovu, Princess Moyo, Godknows Chinguo, Nenero Hove, Hosea Ndlovu, Valising Mutombo, Beulah Ngwenya, Ruth Munhundagwa, Vonai Ngwenya, Nyengeterai Ngandu, Saori Ogura, and Alejandra Cano. Katherine Weatherford Darling, Jenny Reardon, Lizzy
Hare, Andrew Mathews, and Eric Nost gave valuable advice on qualitative analysis, workshop structure, justice framing, and interview questions. We thank the Santa Fe Institute for hosting the Complex Systems Summer School 2015 for which the model was initially developed. Stephen Guerin, Andrew Berdahl, Joshua Epstein, Isaac Ullah, Matthew Potts, and Juan Carlos Castilla gave us a variety of advice on AgentBased Models.

\section{FUNDING INFORMATION}

This work was supported by the United States National Science Foundation [1415130]. NSF had no involvement in study design; collection, analysis, and interpretation of data; writing of the paper; or the decision to submit for publication.

\section{COMPETING INTERESTS}

The authors have no competing interests to declare.

\section{AUTHOR CONTRIBUTIONS}

A. Veski, A.C. Fisher, O.E. Omoju, J. Solera, M.V. Eitzel, and A. Neves were involved with the creation and testing of the model. A. Mawere Ndlovu, K.B. Wilson, A. Changarara, D. Ndlovu, A. Ndlovu, A. Chirindira, and E. Mhike Hove worked with J. Solera and M.V. Eitzel to run modeling workshops and observe community responses. All authors contributed their reflections and analysis of these experiences. M.V. Eitzel, J. Solera, and K.B. Wilson conducted the situational analysis, and M.V. Eitzel conducted all other analyses for the project as well as drafting the manuscript. All authors provided feedback on manuscript drafts.

\section{AUTHOR AFFILIATIONS}

M.V. Eitzel (D) orcid.org/0000-0002-3877-1551

University of California, Santa Cruz, US

Jon Solera

Seven Points Consulting, US

Emmanuel Mhike Hove

The Muonde Trust, ZW

K.B. Wilson

The Muonde Trust, ZW

Abraham Mawere Ndlovu

The Muonde Trust, ZW

Daniel Ndlovu

The Muonde Trust, ZW 
Abraham Changarara

The Muonde Trust, ZW

Alice Ndlovu

The Muonde Trust, ZW

Kleber Neves

Universidade Federal do Rio de Janeiro, BR

\section{Adnomore Chirindira}

The Muonde Trust, ZW

Oluwasola Omoju

National Institute for Legislative and Democratic Studies, NG

\section{Aaron C. Fisher}

Lawrence Livermore National Laboratory, US

\section{André Veski}

Tallinn University of Technology, EE

\section{REFERENCES}

Arnstein, SR. 1969. A ladder of citizen participation. Journal of the American Institute of Planners, 35(4): 216-224. DOI: https:// doi.org/10.1080/01944366908977225

Chilisa, B. 2017. Decolonising transdisciplinary research approaches: an African perspective for enhancing knowledge integration in sustainability science. Sustainability Science, 12: 813-827. DOI: https://doi.org/10.1007/s11625-017-0461-1

Coombes, B, Johnson, JT and Howitt, R. 2014. Indigenous geographies III: Methodological innovation and the unsettling of participatory research. Progress in Human Geography, 38(6): 845-854. DOI: https://doi.org/10.1177/0309132513514723

D'Aquino, P and Papazian, H. 2014. An inclusionary strategy reaching empowering outcomes ten years after a twoyear participatory land uses management. Environmental Management and Sustainable Development, 3: 154. DOI: https://doi.org/10.5296/emsd.v3i2.6595

Eitzel, MV, Cappadonna, J, Santos-Lang, C, Duerr, R, West, SE, Virapongse, A, Kyba, C, Bowser, A, Cooper, C, Sforzi, A, Metcalfe, AN, Harris, ES, Thiel, M, Haklay, M, Ponciano, L, Roche, J, Ceccaroni, L, Shilling, FM, Dörler, D, Heigl, F, Kiessling, T, Davis, BY and Jiang, Q. 2017. Citizen science terminology matters: Exploring key terms. Citizen Science: Theory and Practice, 2: 1-20. DOI: https://doi.org/10.5334/ cstp.96

Eitzel, MV, Fan, C, Solera, J, Mawere Ndlovu, A, Shang, H, Changarara, A, Mhike Hove, E and Wilson, KB. 2016.

Community resilience and the dynamics of relatedness and residence in a rural Zimbabwean village from 1986 to 2010. Proceedings of the Santa Fe Institute 2015 Complex Systems Summer School. Available at: https://santafe.edu/engage/ learn/resources/2015-csss-proceedings.

Eitzel, MV, Mhike Hove, E, Solera, J, Madzoro, S, Changarara, A, Ndlovu, D, Chirindira, A, Ndlovu, A, Gwatipedza, S, Mhizha, M and Ndlovu, M. 2018. Sustainable development as successful technology transfer: Empowerment through teaching, learning, and using digital participatory mapping techniques in Mazvihwa, Zimbabwe. Development Engineering, 3: 96-208. DOI: https://doi.org/10.1016/j.deveng.2018.07.001

Eitzel, MV, Solera, J, Wilson, KB, Neves, K, Fisher, AC, Veski, A, Omoju, OE, Mawere Ndlovu, A and Mhike Hove, E. 2020a. Using mixed methods to construct and analyze a participatory agent-based model of a complex Zimbabwean agro-pastoral system. PloS ONE, 15: e0237638. DOI: https:// doi.org/10.1371/journal.pone.0237638

Eitzel, MV, Solera, J, Wilson, KB, Neves, K, Fisher, AC, Veski, A, Omoju, OE, Mawere Ndlovu, A and Mhike Hove, E. 2020 b. Indigenous climate adaptation sovereignty in a Zimbabwean agro-pastoral system: exploring definitions of sustainability success using a participatory agent-based model. Ecology and Society, 25(4): 13. DOI: https://doi.org/10.5751/ES-11946250413

Estes, N. 2019. Our history is the future: Standing Rock versus the Dakota Access Pipeline, and the long tradition of Indigenous resistance. New York: Verso Books.

Étienne, M. 2014. Companion modelling: a participatory approach to support sustainable development. Berlin/Heidelberg: Springer Science \& Business Media.

Falconi, SM and Palmer, RN. 2017. An interdisciplinary framework for participatory modeling design and evaluation-What makes models effective participatory decision tools? Water Resources Research, 53: 1625-1645. DOI: https://doi. org/10.1002/2016WR019373

Fortmann, L. 2009. Participatory research in conservation and rural livelihoods: doing science together. John Wiley \& Sons.

Gaber, N. 2019. Mobilizing health metrics for the human right to water in Flint and Detroit, Michigan. Health Hum Rights, 21 179-189.

Hartman, BD, Cleveland, DA and Chadwick, OA. 2016. Linking changes in knowledge and attitudes with successful land restoration in indigenous communities. Restoration Ecology, 24: 749-760. DOI: https://doi.org/10.1111/rec.12347

Kalafatis, SE, Libarkin, JC, Whyte, KP and Caldwell, C. 2018. Utilizing the dynamic role of objects to enhance crosscultural climate change collaborations. Weather, Climate, and Society, 11: 113-125. DOI: https://doi.org/10.1175/ WCAS-D-17-0115.1

Kimmerer, R. 2011. Restoration and Reciprocity: The contributions of traditional ecological knowledge. In: Egan, D, Hjerpe, EE and Abrams, J (Eds.), Human Dimensions of Ecological Restoration: Integrating Science, Nature, and Culture, Society for Ecological Restoration. Washington, DC: Island Press/ Center for Resource Economics. pp. 257-276. DOI: https://doi. org/10.5822/978-1-61091-039-2_18

Le Page, C and Perrotton, A. 2017. KILT: a modelling approach based on participatory agent-based simulation of stylized socio-ecosystems to stimulate social learning with local stakeholders, in: International Workshop on Multi-Agent 
Systems and Agent-Based Simulation. Springer, pp. 156-169. DOI: https://doi.org/10.1007/978-3-319-91587-6_11

Lynam, TJP. 2003. Scientific measurement and villager's knowledge: an integrative multi-agent model from the semiarid areas of Zimbabwe. In: Janssen, M (Ed.), Complexity and ecosystem management. The theory and practice of multiagent systems. Cheltenham: Edward Elgar Publishers.

Martinez, D. 1995. Karuk Tribal Module of Mainstem Salmon Watershed Restoration: Karuk Ancestral Lands and People as Reference Ecosystem for Eco-cultural Restoration in Collaborative Ecosystem Management. Unpublished report. On file with U.S. Department of Agriculture, Forest Service, Klamath National Forest, 1312 Fairlane Rd, Yreka, CA 96097.

McGregor, D. 2004. Coming full circle: Indigenous knowledge, environment, and our future. American Indian Quarterly, 28: 385-410. DOI: https://doi.org/10.1353/aiq.2004.0101

Michaels, E. 1993. Bad Aboriginal art: Tradition, media, and technological horizons. University of Minnesota Press.

Mukamuri, BB. 1995. Local environmental conservation strategies: Karanga religion, politics and environmental control. Environment and History, 1: 297-311. DOI: https:// doi.org/10.3197/096734095779522582

Norgaard, KM. 2019. Salmon and acorns feed our people: Colonialism, nature, and social action. New Brunswick: Rutgers University Press. DOI: https://doi. org/10.36019/9780813584225

Ostrom, E, Burger, J, Field, CB, Norgaard, RB and Policansky, D. 1999. Revisiting the commons: local lessons, global challenges. Science, 284: 278-282. DOI: https://doi. org/10.1126/science.284.5412.278

Oteros-Rozas, E, Martín-López, B, Daw, TM, Bohensky, EL, Butler, JRA, Hill, R, Martin-Ortega, J, Quinlan, A, Ravera, F, Ruiz-Mallén, I, Thyresson, M, Mistry, J, Palomo, I, Peterson, GD, Plieninger, T, Waylen, KA, Beach, DM, Bohnet, IC, Hamann, M, Hanspach, J, Hubacek, K, Lavorel, S and Vilardy, SP. 2015. Participatory scenario planning in place-based social-ecological research: insights and experiences from 23 case studies. Ecology and Society, 20: art32. DOI: https://doi. org/10.5751/ES-07985-200432

Pearce, LM. 2019. Critical Histories for Ecological Restoration. PhD Thesis. The Australian National University.

Perrotton, A, de Garine-Wichatitsky, M, Valls-Fox, $\mathbf{H}$ and Le Page, C. 2017. My cattle and your park: codesigning a role-playing game with rural communities to promote multistakeholder dialogue at the edge of protected areas. Ecology and Society, 22(1): 35. DOI: https://doi.org/10.5751/ ES-08962-220135

Prell, C. 2012. Social network analysis: History, theory and methodology. Thousand Oaks: Sage.

Samkange, SJT and Samkange, TM. 1980. Hunhuism Or Ubuntuism: A Zimbabwe Indigenous political philosophy. Salisbury/Harare: Graham Pub.
Shirk, JL, Ballard, HL, Wilderman, CC, Phillips, T, Wiggins, A, Jordan, R, McCallie, E, Minarchek, M, Lewenstein, BV, Krasny, ME and Bonney, R. 2012. Public participation in scientific research: a framework for deliberate design. Ecology and Society, 17: art29. DOI: https://doi.org/10.5751/ES-04705170229

Sium, A, Desai, C and Ritskes, E. 2012. Towards the 'tangible unknown': Decolonization and the Indigenous future. Decolonization: indigeneity, education \& society, 1(1).

Soleri, D and Cleveland, DA. 2005. Scenarios as a tool for eliciting and understanding farmers' biological knowledge. Field Methods, 17: 283-301. DOI: https://doi. org/10.1177/1525822X05277476

Star, SL and Griesemer, JR. 1989. Institutional ecology, 'translations' and boundary objects: amateurs and professionals in Berkeley's Museum of Vertebrate Zoology, 1907-39. Social Studies of Science, 19: 387-420. DOI: https:// doi.org/10.1177/030631289019003001

Tuck, E and Yang, KW. 2012. Decolonization is not a metaphor. Decolonization: Indigeneity, education \& society, 1(1).

Valente, TW. 2006. Communication network analysis and the diffusion of innovations. In: Singhal, A and Dearing, J (Eds.), Communication of Innovations: A Journey with Ev Rogers. New Delhi: Sage. pp. 61-82. DOI: https://doi. org/10.4135/9788132113775.n3

Voinov, A and Gaddis, EB. 2017. Values in participatory modeling: Theory and practice. In: Gray, S, Paolisso, M, Jordan, R, Gray, S (Eds.), Environmental Modeling with Stakeholders: Theory, Methods, and Applications. New York: Springer International Publishing. pp. 47-63. DOI: https://doi.org/10.1007/978-3319-25053-3_3

Voinov, A, Kolagani, N, McCall, MK, Glynn, PD, Kragt, ME, Ostermann, FO, Pierce, SA and Ramu, P. 2016. Modelling with stakeholders - Next generation. Environmental Modelling and Software, 77: 196-220. DOI: https://doi.org/10.1016/j. envsoft.2015.11.016

Walter, M and Andersen, C. 2013. Indigenous statistics: A quantitative research methodology. Walnut Creek: Left Coast Press.

Wholey, JS, Hatry, HP and Newcomer, KE. 2010. Handbook of Practical Program Evaluation. San Francisco: John Wiley \& Sons.

Wilensky, U and Stroup, W. 1999. Learning through participatory simulations: network-based design for systems learning in classrooms. Proc. CSCL, 1: 80. DOI: https://doi. org/10.3115/1150240.1150320

Wilson, KB. 1989. Trees in Fields in Southern Zimbabwe. Journal of Southern African Studies, 15(2): 369-383. DOI: https://doi. org/10.1080/03057078908708205

Wilson, K. 1990. Ecological Dynamics and Human Welfare: a case study of population, health, and nutrition in Zimbabwe (PhD Thesis). University College London. 
Wilson, KB. 1995. "Water used to be scattered in the landscape": local understandings of soil erosion and land use planning in southern Zimbabwe. Environment \& History, 1: 281-296. DOI: https://doi.org/10.3197/096734095779522500

Wilson, NJ, Mutter, E, Inkster, J and Satterfield, T. 2018. Communitybased monitoring as the practice of Indigenous governance: A case study of Indigenous-led water quality monitoring in the
Yukon River Basin. Journal of Environmental Management, 210: 290-298. DOI: https://doi.org/10.1016/j.jenvman.2018.01.020

Yung, L, Louder, L, Gallagher, L, Jones, K and Wyborn, C. 2019. How methods for navigating uncertainty connect science and policy at the water-energy-food nexus. Frontiers in Environmental Science, 7: 37. DOI: https://doi.org/10.3389/ fenvs.2019.00037

TO CITE THIS ARTICLE:

Eitzel, MV, Solera, J, Mhike Hove, E, Wilson, KB, Mawere Ndlovu, A, Ndlovu, D, Changarara, A, Ndlovu, A, Neves, K, Chirindira, A, Omoju, O, Fisher, AC and Veski, A. 2021. Assessing the Potential of Participatory Modeling for Decolonial Restoration of an Agro-Pastoral System in Rural Zimbabwe. Citizen Science: Theory and Practice, 6(1): 2, pp. 1-16. DOI: https://doi.org/10.5334/cstp.339

Submitted: 14 May 2020 Accepted: 18 December 2020 Published: 05 February 2021

COPYRIGHT:

(c) 2021 The Author(s). This is an open-access article distributed under the terms of the Creative Commons Attribution 4.0 International License (CC-BY 4.0), which permits unrestricted use, distribution, and reproduction in any medium, provided the original author and source are credited. See http://creativecommons.org/licenses/by/4.0/.

Citizen Science: Theory and Practice is a peer-reviewed open access journal published by Ubiquity Press.

\section{]u[ ə}

